\title{
OS DESAFIOS DA PÓS-MODERNIDADE PARA O DIREITO PENAL BRASILEIRO: REFLEXÕES A PARTIR DA CONTRIBUIÇÃO DE ANTONIO LUIS CHAVES CAMARGO
}

\author{
THE CHALLENGES OF POSTMODERNITY FOR BRAZILIAN CRIMINAL LAW: \\ REFLECTIONS ON THE CONTRIBUTION OF ANTONIO LUIS CHAVES CAMARGO
}

\author{
Alamiro Velludo Salvador Netto* \\ Luciano Anderson de Souza** \\ Beatriz Corrêa Camargo ${ }^{* * *}$
}

\begin{abstract}
Resumo:
O presente artigo propõe uma leitura do momento histórico que caracteriza o pós-finalismo no Direito Penal. Parte-se, neste intento, da concepção de pósmodernidade programaticamente apresentada por Antonio Luis Chaves Camargo ao final dos anos 90. A partir de provocações do antigo professor da FDUSP, pontuase a contribuição da teoria dos sistemas e da teoria discursiva do Direito para esse ramo jurídico.
\end{abstract}

Palavras-chave: Funcionalismo. Teoria dos sistemas. Teoria discursiva do Direito. Pós-modernidade. Direito Penal.

\begin{abstract}
:
This paper proposes a reading of the historical moment that characterizes postfinalism in Criminal Law. In this sense, we start from the conception of postmodernity programmatically presented by Antonio Luis Chaves Camargo at the end of the 90's. Taking the provocations of the former professor of FDUSP as a starting point, this article presents the contribution of systems theory and discursive theory of law for this legal branch.
\end{abstract}

Keywords: Functionalism. Systems theory. Discursive theory of law. Postmodernity. Criminal Law.

\footnotetext{
Professor Titular de Direito Penal da Faculdade de Direito da Universidade de São Paulo (USP). LivreDocente, Doutor e Mestre pela USP.

** Professor Associado de Direito Penal da Faculdade de Direito da Universidade de São Paulo (USP). LivreDocente, Doutor e Mestre pela USP.

*** Professora Doutora de Direito Penal da Faculdade de Direito da Universidade Federal de Uberlândia (UFU). Doutora e Pós-Doutora pela USP.
} 
1. Introdução

No ano de 1996, o falecido professor da Universidade de São Paulo, Antonio Luis Chaves Camargo, discorria sobre os reflexos da modernidade para o Direito Penal no artigo intitulado "Contradições da modernidade e Direito Penal” (CAMARGO, A., 1996). $\mathrm{O}$ artigo, eivado de particular originalidade perante o contexto da produção jurídico-penal brasileira naquele momento, suscita reflexões que a nosso ver ultrapassam o interesse histórico, já que oferece questões de fundo ainda não resolvidas na sociedade atual.

Ao contrário do que se poderia imaginar, os problemas suscitados por Chaves Camargo em seu estudo não se deixam reduzir a apresentar das contradições de um tempo que passou. Mais do que isso, a análise do autor, em verdade, situa os desafios atuais da chamada pós-modernidade para o sistema punitivo que temos ainda hoje, e isso em diversas dimensões. ${ }^{1}$ Dado o seu objeto teórico, pode-se dizer que o texto escrito por Chaves Camargo em 1996 se dirigia primariamente à produção científica, isto é, aos pesquisadores acadêmicos. Todavia, a abordagem oferecida por Chaves Camargo é mais ampla. Ela chama à responsabilidade os juristas como um todo, o que inclui também professores, mas igualmente, e sobretudo, os juristas implicados na prática forense, que são convocados pelo autor a reverem sua formação técnica no propósito de uma atuação mais consciente na construção do Direito Penal.

O presente texto propõe uma leitura do Direito Penal, particularmente o brasileiro, no momento histórico atual, caracterizado mais amplamente como "pósfinalista". Isso será feito a partir da programática contribuição oferecida por Antonio Luis Chaves Camargo no artigo mencionado. Nesse espectro, defende-se que uma reflexão sobre os fundamentos teóricos e sociais do Direito Penal oferece a oportunidade de pôr à prova antigas crenças, ainda arraigadas no Brasil, as quais comprometem a compreensão sobre o funcionamento do sistema penal e a sua devida legitimação. Para tanto, mostra-se indispensável imiscuir-se sobre o pensamento funcionalista, em especial para discutir a influência de autores como Niklas Luhmann, bem como os aportes oferecidos por Jürgen Habermas e Klaus Günther.

2. A crítica da racionalidade penal moderna no Brasil sob a ótica de Antonio Luis Chaves Camargo

No referido estudo de 1996, Chaves Camargo se debruça sobre duas ordens de problemas sobre os quais deve o penalista ao menos conscientizar-se. Primeiramente,

Os "desafios da pós-modernidade" nunca deixaram de ser objeto de estudo na obra do autor, o que se nota particularmente em seu estudo Imputação objetiva e direito penal brasileiro (CAMARGO, A., 2002). 
o autor apresenta aquilo que entende serem os desafios da pós-modernidade para o Direito de uma maneira mais geral, cuja realidade cabe ser compreendida e aceita pelo jurista. Em um segundo momento, o autor passa para uma análise das implicações mais imediatas dessa visão para a autocompreensão da dogmática penal, assim como para as transformações pelas quais passavam e haveriam de passar o sistema punitivo.

Sabiamente, o autor não se dispôs a conceituar a pós-modernidade. Note-se que sutileza dessa estratégia não se justifica apenas perante a questionável contribuição de um esforço definitório cuja precisão, afinal, é duvidosa por tratar-se do complexo momento presente em que se encontrava o autor. Ocorre simplesmente que o grande ponto para pensar a pós-modernidade reside na necessidade de lidar com o legado da modernidade, vale dizer, com a herança cultural que caracteriza as contradições vividas nos dias de hoje, como coloca Chaves Camargo. Assim, o autor oferece um conceito de modernidade no Direito Penal que representaria o anacronismo de ideias e práticas ainda presentes no contexto brasileiro. Embora "modernidade" não seja um conceito exclusivo das ciências penais, sua concepção se estende às origens do Direito Penal clássico, conforme elucida Chaves Camargo:

Desde Beccaria, em 1764, foi clara a marca das idéias iluministas no Direito Penal, que caracterizaram a obra de Filangieri, Feurbach, Bentham, Carmignani, Rossi, Carrara e outros que seguiram as diretrizes da chamada Escola Clássica, no seu período inicial. O Direito Penal assentouse em princípios rígidos e conceitos absolutos, dando por encerrada qualquer mudança na sua metodologia. As reações a estes métodos não demoraram a surgir, com a volta as ciências naturais, como um interregno, uma contestação ao ideal iluminista predominante. Surge, como marco conceitual de uma nova era, o neologismo "modernidade", na busca de uma sustentação sociológica de uma realidade, insatisfeita e saturada com a utopia iluminista ou com o próprio sentido natural das ciências sociais. O Direito Penal tem a interferência desta designação, e recebe da filosofia kantiana seus primeiros traços, de um racionalismo totalizador, estabelecendo um conceito apriorístico e transcendental para o crime. (CAMARGO, A., 1996, p. 114).

Importante destacar nessa passagem o propósito implícito na criação do conceito de modernidade. Trata-se de um intuito iminentemente crítico, conforme indica o autor. No contexto penal, segundo Chaves Camargo, categorizar a modernidade permite traçar uma oposição ao "racionalismo totalizador" que caracteriza as escolas clássicas e positivistas, as quais - a seu ver, nocivamente - estabelecem "um conceito apriorístico e transcendental para o crime". 
Partindo da linha de análise proposta por Chaves Camargo, a filosofia adquire papel fundamental para o penalista crítico, cuja formação filosófica seria a única capaz de habilitá-lo a compreender a gramática subjacente à investigação sobre as escolas penais. Nesse sentido, para o autor, as escolas penais não deveriam ser estudadas desde a perspectiva da mera curiosidade sobre a história das ideias jurídicas. Antes disso, Chaves Camargo enxergava no método próprio de cada escola de pensamento a expressão de uma visão de mundo. Ou seja: cada escola penal reflete um modo peculiar de se compreender o indivíduo, a natureza das relações humanas, a sociedade, a política e o direito, além de uma maneira de se posicionar perante tudo isso. Sendo os óculos com os quais o jurista enxerga a realidade das coisas, a metodologia jurídico-penal constitui o componente básico e primordial a influenciar as decisões jurídicas, determinando, em última instância, os limites da intervenção do Direito nas relações sociais. (CAMARGO, A., 1996, p. 116).

Logo, a contribuição da Filosofia para o Direito diz respeito à definição dos próprios problemas que devem ocupar o jurista, definindo, por consequência, o objeto legítimo de uma pesquisa científica na área jurídica. Semelhante problemática foi abordada por Jürgen Habermas a partir de duas questões que considerava fundamentais na atualidade. A primeira delas se relaciona com a identificação daquilo que viria a constituir a crise do Direito nos dias de hoje. A segunda questão se refere ao papel do Direito na sociedade, que igualmente deixa de ser visto como o eixo central de todas as formas de interação social. (HABERMAS, 2005, p. 179-190). Ambas as questões se colocam provocativamente no texto de Chaves Camargo, conforme avaliaremos a seguir.

Nesse contexto, mais relevante do que a preocupação com o surgimento de novos desafios de ordem material para a ciência jurídico-penal, nos parece ser uma reflexão sobre a concepção da pós-modernidade como uma mudança de atitude perante o mundo. Para Chaves Camargo, a pós-modernidade refletia a angústia inerente ao sujeito que reconhece a necessidade de agir, porém, se vê confrontado com a impotência de qualquer intuito no sentido de influenciar o turbilhão de transformações sociais e tecnológicas ocorridas nas últimas décadas. Daí a ideia de que os juristas em vão ignoram a pós-modernidade quando preferem se ater ao formalismo jurídico, em uma tentativa de manter o controle, puramente fictício, sobre o objeto da regulação jurídica. (CAMARGO, A., 1996, p. 116 et seq.). Assim, a crítica de Chaves Camargo ao positivismo jurídico ancorado na modernidade se ampara na ilusória imagem de que seria possível sustentar a legitimidade e a eficácia da norma penal à maneira de um avestruz que esconde sua cabeça debaixo da terra.

Deste modo, a possibilidade mesma de lidar com os problemas gerados pela pós-modernidade estaria condicionada a uma postura cognitiva do jurista, a quem cabe reavaliar o seu papel no meio de atuação em que se encontra, seja ele prático ou acadêmico. O necessário giro cognitivo passa, assim, pela constatação de que "a nossa 
vaidade jurídica nos impede a reflexão humilde e silenciosa" (CAMARGO, A., 1996, p. 117). Ao penalista na pós-modernidade seria indispensável, portanto, a postura de um observador, que sabe de sua diminuta capacidade de transformação através da produção científica e do processo de tomada de decisão.

\section{O Direito Penal entre a teoria crítica e a teoria dos sistemas}

A segunda metade do século 20 se caracterizou por uma ampla crise nas principais concepções acerca do Direito. Nos dizeres de Celso Campilongo (2000), o que se teve foi um definitivo esgotamento dos paradigmas estritamente positivistas ou daqueles outros mais próximos do jusnaturalismo.

Toda uma nova gramática foi gradativamente sendo incorporada, desde suas origens filosóficas e sociológicas, ao universo do Direito. A alteração da realidade social demandou uma profunda modificação das ciências sociais. No pensamento jurídico, vislumbrou-se, por um lado, a influência das teorias críticas, que remontam, com maior ou menor intensidade, ao pensamento marxista. De outro lado, fizeram-se presentes as concepções genericamente entendidas como funcionalistas, as quais, ao seu turno, resgatavam o pensamento de Durkheim ainda no final do século 19.

Desta forma, pode-se afirmar que, na esteira das ciências sociais, a ciência do Direito caminhou ao longo da segunda metade do século 20 para dois rumos de grande importância para a ciência jurídico-penal: o do pensamento sistêmico e o da teoria crítica. Niklas Luhmann é um exemplo deste último caminho. Considerado um dos mais importantes representantes da sociologia alemã, o autor trabalha com o conceito de sistemas autopoiéticos como forma de reduzir a complexidade social.

$\mathrm{Na}$ outra direção, inserida na tradição da teoria crítica, está Habermas, conhecido por suas teorias de racionalidade comunicativa na esfera pública. Habermas é considerado um dos herdeiros mais importantes da Escola filosófica de Frankfurt, uma das principais correntes do marxismo cultural. Habermas tem como ponto de partida a ideia da ética comunicativa e da razão objetiva de Theodor Adorno. Por fim, Klaus Günther pode ser visto como um discípulo de Habermas, defensor da teoria do discurso e responsável por algumas releituras de conceitos habermasianos.

Em seu estudo, Chaves Camargo sintetiza a importância de ambos os desenvolvimentos para o Direito Penal no uso que faz da concepção de pós-modernidade. Para o autor, as implicações da pós-modernidade em nosso país adquire o caráter de um estado de crise de dupla dimensão. A primeira delas, característica do mencionado esgotamento dos paradigmas até então aceitos para compreender o Direito e a sua função. As chamadas crises de centralidade e de legitimidade do Direito, sobre as quais nos debruçaremos adiante, já batiam há muito às portas do Direito Penal no Brasil, conforme 
alertava Chaves Camargo. A dimensão dessa crise tem ancoragem sociológica, na medida em que deriva das transformações e complexificações da sociedade. O diferencial da realidade brasileira, segundo pontuava o autor naquele momento, era uma dimensão adicional de crise, que pode ser classificada como uma "crise de visão", ou seja, a enorme dificuldade do jurista brasileiro em enxergar a realidade dos novos tempos, como se pode depreender da seguinte passagem:

Vivemos ainda o reflexo da modernidade. Mesmo sentindo que o Direito Penal não possui instrumentos capazes de resolver o problema do aumento da criminalidade, muito menos de legitimar-se no meio social, insistimos no positivismo jurídico neokantiano. Tudo está na lei e na sua interpretação. O Direito é reconhecido a partir de elementos categoriais a priori, sendo função do jurista a determinação do conteúdo das normas gerais de certo âmbito material. As soluções fluirão rápidas, com as mudanças da legislação e a celeridade dos processos. Usa-se uma roupagem nova para idéias já superadas e frágeis na visão do homem atual. Esta arrogância positivista jurídica se faz presente, também, nos meios universitários. A denominada pós-modernidade, ainda debatida e questionada, com sua postura crítica, não foi avistada pela universidade brasileira, em razão do tradicionalismo jurídico que naufraga, sem rumo, entre a magnitude das aulas ou a extrema praticidade dos métodos, massificando o aluno, sem formar o jurista, mas o 'rábula'. (CAMARGO, A., 1996, p. 115).

Os desafios da sociedade pós-moderna suscitam, assim, diferentes diagnósticos e posturas em relação aos problemas levantados. No presente ensaio, serão traçados alguns deles a partir da crise do Direito Penal indicada por Chaves Camargo.

A presente análise focará em duas questões que a nosso ver representam relevantes contribuições da teoria crítica e da teoria dos sistemas para a ciência penal contemporânea. A teoria crítica, desde uma perspectiva filosófica, apresenta a crise de legitimidade do Direito como tema a ser enfrentado pela teoria do delito, na fundamentação da intervenção penal. A teoria dos sistemas aponta, a partir do viés sociológico, a necessidade de se refletir sobre as funções e as limitações da pena na sociedade atual.

\section{O Direito como sistema social: norma e expectativa}

A necessidade de uma reflexão sobre o momento atravessado pela sociedade contemporânea era reconhecida por Chaves Camargo como condição indispensável para superar "uma visão ilusória do papel do Direito" (CAMARGO, A., 1996, p. 117) e ampliar o espectro de análise de modo a abarcar a complexidade das relações entre o crime e a sociedade. (CAMARGO, A., 1996, p. 126). 
Em Habermas, trata-se mais explicitamente de questionar a premissa segundo a qual o Direito seria a estrutura central da sociedade, responsável por resolver intrincados problemas de ordem política e econômica, por exemplo. Em outras palavras, o ponto a ser indagado se refere à ideia de que seria possível fazer uma leitura da sociedade a partir do direito, sendo que o desenvolvimento das ciências sociais contemporâneas indica para o caminho justamente contrário, isto é, uma simples leitura do direito através de uma perspectiva social mais ampla. (HABERMAS, 2005, p. 186).

Tal reflexão é tributária do aporte teórico luhmanniano. Conforme observa Marcelo Neves, a teoria dos sistemas chama atenção para a inviabilidade de qualquer modelo que procure descrever ou fundamentar as interações sociais a partir de um único mecanismo, seja ele a religião, o direito, o poder, a economia, a luta de classes, etc. As sociedades contemporâneas se caracterizam pela existência não de um centro a coordenar sua reprodução, mas são, antes disso, constituídas de forma multicêntrica e policontextual, com sistemas que coexistem e concorrem entre si. De acordo com o autor, não há um centro da sociedade que possa ter uma posição privilegiada para observação ou explicação, assim como não há um sistema ou mecanismo social a partir do qual todos os outros possam ser compreendidos. Logo, se mostra pouco convincente uma explicação da sociedade pautada exclusivamente na relação de poder, como pretendia Foucault, na luta de classes como apregoava Marx ou mesmo no agir comunicativo de Habermas. (NEVES, 2004, p. 127).

Trata-se de uma mudança de perspectiva bastante significativa para o cientista penal, pois implica reconhecer que o Direito é apenas um subsistema dentre outros no conjunto social. Com efeito, o Direito irrita e é irritado por outros subsistemas, como o político e o econômico, além de interferir e se acoplar com eles. Mas isso é muito diferente de considerar que o Direito determina a lógica e a reprodução de todos os subsistemas com os quais se comunica. O âmbito de alcance e ingerência do Direito é, portanto, muito mais limitado do que aspiravam os juristas europeus até meados do século passado.

Nesse contexto, e para que se possa entender o porquê de uma teoria dos sistemas, é necessário verificar um caminho relativamente linear daquilo que se pode chamar de desencantamento do mundo. Isto é: se a grande virtude da modernidade foi desencantar o mundo, afastando as dimensões metafísicas e religiosas como fatores determinantes da vida entre os homens, a pós-modernidade atuou, ela mesma, nos dizeres de Raffaele de Giorgi (2006, p. 119 et seq.), como uma nova espécie de desencantamento. O desafio do homem torna-se a busca de um certo grau de controlabilidade definido pela maneira que os homens devem lidar não mais com a certeza, mas com a contingência, o 
inesperado, de tal sorte que considera o autor italiano inclusive ser o risco, palavra tão comum na literatura sociológica, uma forma de vínculo com o futuro. ${ }^{2}$

O pensamento de Luhmann foi, ao menos no seu início, bastante influenciado pela concepção funcional ou sociológico-funcional. Para compreender essa afirmativa é necessário entender a maneira mais basal de organização de vida social, ou seja, a forma como seres humanos constroem sua sociedade e em consequência a regulam. Esse modo de pensar, muito mais próximo de uma visão social de consenso do que de conflito, toma o mundo como um conjunto de indivíduos, vistos abstratamente na sua singularidade.

Ao contrário da visão de grupos ou classes comumente vinculados a uma perspectiva materialista, o funcionalismo propõe uma composição social atomizada, pulverizada na igualdade formal. Para tanto, vale a comparação da sociedade como um organismo onde os homens seriam como células e a coletividade esta marcada por relações específicas, as quais se destinam à estabilidade e padronização das condutas. Nesse sentido, e nas palavras de Alaôr Café (2010, p. 99 et seq.), a vida social seria definida como funcionamento da estrutura social, garantida por atividades institucionalizadas que se mantém por meio da repetitividade, ou seja, haveria uma continuidade estrutural.

Aparece aí como modelo dessa repetição e continuidade a figura dos papéis sociais, ou seja, códigos de condutas fixadas para um atuar em comunidade de tal modo que a cada indivíduo cumpre exercer liturgias, atuações e expectativas próprias dos variados papéis que cumprem. Há uma tábua de comportamentos a se realizar, por exemplo, no cerne da família, do clube, da empresa, da universidade. É exatamente este cumprimento de expectativas sociais mútuas que permitem a convergência entre os cidadãos, realizandose aqueles valores que são identitários de uma determinada sociedade.

Nesse contexto o Direito aparece como um sistema próprio e dotado de um código próprio, como afirma Luhmann (1983): o ponto de partida de uma teoria dos sistemas para a sociologia deve derivar de um preceito teórico baseado na diferença. Nesse ponto, o Direito diferencia-se enquanto sistema operando no código legal/ilegal e responsabilizando-se pela institucionalização de expectativas normativas. Aqui vale a distinção feita por Luhmann (1983, p. 42 et seq.) entre expectativas normativas e expectativas cognitivas.

2 Não obstante a efetiva perda de certeza e controle, há vantagens e perigos no acolhimento de um pensamento sistemático. Vantagens de um pensamento sistemático seriam a de facilitar o exame de casos, a de permitir a ordenação do sistema como meio de uma aplicação uniforme e diferenciada no Direito e a simplificação e melhor manejo do Direito. Demais disso, o contexto sistemático mostrar-se-ia como guia para a elaboração e desenvolvimento do Direito. Por sua vez, perigos seriam o esquecimento da Justiça no caso concreto, a redução das possibilidades da resolução de problemas, a conformação de deduções sistemáticas não legitimáveis político-criminalmente e o emprego de conceitos demasiadamente abstratos. Nesse sentido, Roxin (2008, p. 206-215). 
De um lado, aquelas chamadas cognitivas, que advém do conhecimento, não admitem desilusão. Basta imaginar a lei da física que atesta que o metal quando esquentado se dilata. Caso, num dado momento, quando esquentado, um metal surpreendentemente se contrair, haverá uma total ruptura da expectativa cognitiva, obrigando a revisão dos conhecimentos que lhes dão sustentação.

Por outro lado, existem as expectativas normativas, que não advêm do conhecimento, mas advém das normas, dentre elas, aquelas penais e admitem a desilusão, ou seja, o descumprimento destas mesmas normas. Diferentemente das expectativas baseadas na cognição, as normas não se modificam perante a frustração da expectativa de seu cumprimento. A pena ou sanção jurídica apareceriam aí como um elemento de recuperação da confiança que foi abalada pela prática ilegal do infrator.

Essa construção sistemática ganha bastante sentido em uma sociedade de contatos anônimos, na qual não se conhece o outro, e por esta mesma razão a expectativa acerca do comportamento alheio é cada vez mais dada pelas normas, gerais e impessoais, do que por relações prévias de amizade, parentesco ou profissionais. Por conseguinte, é possível asseverar que o Direito, em geral, e o Direito Penal, em particular, corroboram estas expectativas. Nesse ponto, mister se faz observar que tal perspectiva sistêmica não se limita ao universo do Direito, eis que o sistema jurídico convive com uma série de outros. Bastante ilustrativo a respeito é o pensamento de Maturana e Varela (1980), que praticamente inauguram o conceito de autopoiese originalmente pensado para as ciências biológicas, e depois transposto por Gunther Teubner (1989, p. 139) para as ciências sociais.

Em sua proposta originária, referida concepção permite demonstrar com clareza as relações entre os sistemas. Conforme Maturana e Varela, o ser humano ou organismo vivo atua como um sistema operativamente fechado, mas cognitivamente aberto. Isso significa, primeiramente, que o ser vivo como sistema fechado repete suas operações vitais internamente, recorrendo-se a si mesmo e à sua própria constituição. Porém, ao mesmo tempo é aberto, pois sente os influxos do meio envolvente - nas palavras de Luhmann, o sistema sente, no entorno, suas irritações e perturbações.

Imagine, a título de ilustração, o frio como uma irritação do meio envolvente, ou input. O corpo humano reagiria a tal input acelerando o metabolismo e mantendo a temperatura interna em padrões aptos a conviver naquele ambiente menos favorável. O mesmo pode ser pensado em relação ao Direito Penal, que recebe influxos do seu entorno, advindos de sua relação com outros sistemas. Por exemplo, a sensação social de insegurança (input) faz com que o sistema jurídico reaja por meio de outputs que será um rearranjo da estratégia jurídica importando, e.g., no maior recrudescimento e repressão.

O Direito, assim, ao garantir as expectativas sociais, o faz por fontes próprias. No entanto, a motivação e a intensidade de suas respostas são reações às irritações 
advindas do meio envolvente dos outros sistemas sociais. Ocorre que, se no corpo humano a reação advém de uma ordem natural, biológica ou de causalidade, no Direito trata-se de uma mediação política ou de uma relação de sentido. Essa construção luhmanniana é, por um lado, capaz de absorver nesta convivência mútua entre sistemas a complexidade social, percebendo os impactos recíprocos entre sistema jurídico econômico e político, ao mesmo tempo em que supera uma tentativa de explicação unilateral da sociedade.

O impacto da concepção luhmanniana aparece para muitos autores como determinante do pensamento a ser desenvolvido por Günther Jakobs (como se vê, por exemplo, em JAKOBS, 1995, p. 845-847). É verdade que autorizadas vozes também afirmam uma forte influência do pensamento hegeliano na construção de Jakobs, além do próprio autor. Exemplo nesse sentido é Michael Pawlik (2016), que afasta Jakobs de maiores inspirações luhmannianas, embora assuma as recorrentes referenciais.

Referida influência do pensamento de Jakobs no pensamento penal contemporâneo é acusada de apresentar um caráter conservador, formalista, despreocupado com o seu conteúdo e, verdadeiramente, esvaziador do aspecto social do Direito Penal (SCHÜNEMANN, 1996, p. 189, 208 et seq.). Tal perspectiva, a qual esgota o Direito Penal na garantia de expectativas normativas, e em consequência entende o crime como um fator comunicacional de abalo à confiança ou como desilusão, acabaria por justificar a pena desde um viés meramente formal. Assim, a necessidade de punição aparece tão somente em razão de uma suposta lesividade sistêmica, que se justifica de maneira absolutamente abstrata. Princípios jurídicos como a ofensividade, o apego a teses constitucionais, a garantia de proporcionalidade de pena, restam igualmente prejudicados por uma defesa do sistema jurídico em face dessas "lesividades a instâncias".

$\mathrm{Na}$ atualidade, pode-se afirmar, fazendo uso da linguagem luhmanniana, que dentre os principais fatores de irritação sobre o sistema jurídico-penal se encontram as transformações de ordem técnica e os novos modos de organização econômica e política, que no contexto da globalização precipitam o surgimento de outra criminalidade, organizada transnacionalmente, com efeitos potenciais de largas proporções. O Direito Penal é então chamado a lidar com riscos de dimensões ainda desconhecidas, em áreas de alto nível de complexidade, tais como a internet e o sistema financeiro internacional. (SIEBER, 2008, p. 278 et seq.). Com isso, o sistema se expande, por exemplo, para o âmbito de persecução penal em nível internacional. (SIEBER, 2008, p. 271 et seq.).

No que se refere à teoria do delito, toda a recente discussão sobre as fronteiras e as novas funções do Direito Penal representa o intento de superação da modernidade. Segundo observa Chaves Camargo, essa tentativa contém uma dupla contradição, a qual se estabelece a partir da autorreferencialidade com que o penalista compreende, primeiro, os fins da pena e, segundo, a sua fundamentação. São contradições que se encontram nas requentadas discussões sobre as teorias retributivas e preventivas clássicas, bem como 
sobre os limites da criminalização de condutas. Conforme sugere o autor, a dificuldade de enxergar o problema da pena para além do sistema do Direito Penal impede a realização de uma observação crítica sobre o próprio sistema punitivo, dificultando a reflexão do jurista sobre as consequências da intervenção do Direito Penal na sociedade.

Para Chaves Camargo, as dificuldades práticas da autorreferencialidade do sistema penal, no que se refere às contradições sobre os fins da pena, ficavam muito claras na questão do encarceramento em massa. Nesse sentido, o autor concluía que as teorias retributivas clássicas da pena não eram capazes de oferecer subsídio a uma reforma do sistema penal que pudesse restringir a pena privativa de liberdade apenas para os casos mais graves. Afinal, a compreensão de que a pena é um "castigo" devido ao mal praticado impede qualquer flexibilização do princípio da obrigatoriedade da ação penal (CAMARGO, A., 1996, p. 126).

Ao mesmo tempo, embora represente um olhar do jurista para as consequências da pena na sociedade, o giro preventivo ocasionado pelo positivismo naturalista em fins do século 19 tem como premissa uma concepção positivista de sociedade, cujo futuro é regido por leis naturais aptas a direcionar o desenvolvimento da sociedade. Sob essa perspectiva, a aplicação da pena é simplesmente indispensável, já que os efeitos de prevenção negativa e ressocialização promovem, segundo essa lógica, o progresso da sociedade. Deixar de aplicar a pena seria, portanto, uma involução. Logo, a tímida abertura para as consequências da pena na sociedade operada pelas escolas positivistas esbarraria em uma percepção deficitária dessas escolas quanto ao entorno de atuação penal.

Por outro lado, a autorreferencialidade da fundamentação da pena na modernidade não permitiria à ciência penal tampouco desenvolver uma reflexão sobre a dimensão valorativa de respeito à liberdade individual e de proteção de bens fundamentais. Assim, faltam as bases para os princípios cuja observância é indispensável para a legitimação da intervenção penal.

Por óbvio, a necessidade de legitimação do Direito Penal em um mundo no qual a pena deixa de configurar uma resposta inquestionável frente ao delito faz com que não seja suficiente, para semelhante fundamentação, apenas colocar na balança os interesses de uma maioria contra a pessoa do criminoso a ser "neutralizado" por meio da pena, o que tem sido suficientemente feito por meio da relevância dada ao problema da reincidência, que até hoje constitui obstáculo para benefícios e substitutivos à pena de prisão, além de figurar de maneira indiscriminada como circunstância agravante da pena, segundo observara Chaves Camargo (1996, p. 126). O desafio da legitimação da pena, na pós-modernidade, pressupõe, antes de tudo, considerar que os Direitos fundamentais do potencial criminoso constituem eles mesmos interesses a serem protegidos pelo Direito 
(HASSEMER, 2007, p. 98 et seq.). Somente perspectiva oferece as bases necessárias para um Direito Penal de ultima ratio. (CAMARGO, A., 1996, p. 126).

\section{A crise de legitimidade do Direito Penal}

A essa altura cabe indagar qual seria, afinal, a natureza da crise enfrentada pelo Direito Penal na pós-modernidade. Tratar-se-ia da ausência de parâmetros ante um mundo mergulhado em profundas transformações de natureza tecnológica? São as transformações nas relações sociais? Seriam os reflexos do desencantamento com as instituições, a exemplo do que vivenciamos no Brasil sob a ideia de ativismo judicial, dramatizado pela ausência de previsibilidade e racionalidade nas decisões judiciais?

Habermas sugeriu compreender a questão sob uma ótica mais profunda. Em realidade, deveríamos reconhecer o fato de que vivemos em uma época na qual é antes de tudo a própria ausência de uma racionalidade universal que faz perder sentido a manutenção do ideal moderno de controle e previsibilidade assegurado a partir da criação de leis. Estas, aplicadas por uma jurisprudência obrigada pela razão, cujo papel se esgotaria em fechar lacunas de indeterminação do texto positivado (HABERMAS, 2005, p. 183 et seq.; nesse sentido, igualmente, CAMARGO, A., 1996, p. 124).

Desta sorte, a gênese da reconhecida crise do Direito se encontraria na ausência de consenso sobre os modelos sociais que devem nortear a (re)produção do Direito, o que faz com que a jurisprudência não possa contar ela mesma com a existência de um paradigma universalmente aceito de justiça para nortear as suas escolhas (HABERMAS, 2005, p. 185).

A esse respeito, Chaves Camargo atentava para a necessidade de os juristas brasileiros aceitarem o diagnóstico da "ausência de verdade" não apenas em âmbito teórico-acadêmico, mas, sobretudo, no âmbito prático-forense. O passo para uma relativização de perspectivas sobre os valores protegidos e afetados com a tutela penal seria de importância fundamental para que se pudesse tornar mais complexas as análises acadêmicas e as discussões dos casos apresentados ao juiz, sugerindo, desta forma, que se superasse a simplificação ilusória dos problemas sociais manejados pelo poder judiciário (CAMARGO, A., 1996, p. 126).

Com Habermas, o que pode ser dito é que não há uma interpretação verdadeira, absoluta, mas sim aquela resultante de uma determinada compreensão de mundo ou de mundo da vida. Nesse sentido, a previsibilidade e a ordenação social derivam menos de algo pretensamente verdadeiro e obviamente justo, e mais de opções, as quais devem ser eleitas num espaço de debate destinado a receber o melhor argumento. A premissa da qual se parte é a possibilidade de comunicação entre indivíduos, a qual permite que os problemas de relacionamento social sejam discutidos racionalmente. $\mathrm{O}$ consenso sobre 
as decisões que devem ser tomadas na esfera política não é dado categoricamente, e sim alcançado de maneira argumentativa, em sede provisória (HERRERO, 1979, p. 31-36). ${ }^{3}$ Tal premissa desloca o eixo de atenção do cientista penal para a relação entre o direito e a democracia, o que talvez constitua uma das principais contribuições da teoria crítica para a ciência penal nos dias atuais. ${ }^{4}$

Note-se a diferença, para o Direito Penal, de uma abordagem como essa em comparação com a narrativa moderna. Conforme observava Chaves Camargo, embora o racionalismo universalizante tivesse se iniciado na escola clássica, intensificando-se no positivismo normativista de Karl Binding, seria apenas no positivismo naturalista de Franz von Liszt que ele atingiria o seu auge. No naturalismo, a completa ausência de um lugar para a filosofia, bem como a premissa de que não caberia à ciência penal qualquer reflexão sobre valores, constituíam pressupostos que anulavam qualquer possibilidade de controvérsia sobre a compreensão dos institutos penais e a interpretação da lei (CAMARGO, A., 1996, p. 118).

Nesse sentido, Chaves Camargo indicou dois pontos centrais da teoria do delito em que se expressa a questão da ruptura com uma racionalidade universal na atualidade. O mais óbvio se percebe no âmbito da tipicidade. De acordo com o autor, as premissas da certeza e da funcionalidade, próprias da modernidade, fazem com que a verificação da tipicidade penal se reduza, de maneira simplista, na apuração do nexo causal entre o resultado e a conduta do agente. Em suas palavras, esse modo de proceder “excluía qualquer aspecto interpretativo, pois a 'verdade' empírica levaria, com certeza, à conclusão lógica” (CAMARGO, A., 1996, p. 120).

Neste tocante, vale salientar que a pretensão de se operar uma subsunção automática do comportamento à norma se mostra inadequada não apenas sob a perspectiva linguístico-pragmática, de interpretação da lei penal. Antes disso, é preciso indagar qual o conceito de responsabilidade que está orientando o processo de responsabilização penal. Nesse sentido, conforme bem aponta Klaus Günther, o dissenso também se estende aos critérios escolhidos para a atribuição de responsabilidade, que podem muito bem ter a sua validade questionada pelos sujeitos envolvidos nesse processo. ${ }^{5}$

3 Sobre a teoria e a ética do discurso habermasiana e sua transposição para a fundamentação do Direito Penal, Günther (1991, p. 205 et seq.).

4 Conforme observam Marta Machado e Flavia Püschel (2009), não foram muitos os autores da tradição da teoria crítica que se dedicaram a escrever sobre o Direito. Além dos estudos de Habermas sobre direito e democracia, as autoras ainda lembram a importância, para o direito, das obras de Franz Neumann e Otto Kirchheimer.

5 Desta sorte, o autor enfatiza a existência de modelos dogmáticos em disputa, buscando uma formulação dos processos de imputação a partir da qual as decisões tomadas em um processo de deliberação no Estado Democrático de Direito penetrem em um sistema jurídico. Ao fazer isso, vincula as decisões sobre a imputação de responsabilidade por culpa às normas e regras de imputação legitimamente criadas pelos 
Assim, a formulação do conceito de responsabilidade deve derivar antes da dinâmica de consensos possíveis em face da construção do Direito, os quais se apresentam de maneira necessariamente contingente. A predominante compreensão sobre a responsabilidade penal não impede, por exemplo, que a simples relação causal seja um fator exclusivo de imputação de responsabilidade. Se assim fosse, deveria haver sempre uma eterna busca pelo culpado, tais como atribuir eventuais problemas ambientais àqueles sujeitos que utilizam regularmente o seu automóvel.

Percebe Günther que a construção do conceito de responsabilidade na sociedade complexa contemporânea, se por um lado valoriza o homem como autorresponsável e racional, por outro importa em ônus e limitações existenciais. Esse posicionamento repercute no problema da imputação no sistema penal, pois verifica que imputar um fato a alguém, lhe atribuindo como obra sua, é antes de tudo um fenômeno normativo, o qual deve se dar em conformidade aos padrões de uma determinada comunidade.

Com isso, adentramos no segundo aspecto do diagnóstico traçado por Chaves Camargo relativamente aos desafios que se descortinam ao Direito Penal quando, a partir da influência da teoria crítica na filosofia, é feita a passagem de uma narrativa alicerçada em leis causais e imperativos categóricos para um discurso que se ampara nas concepções de comunicação, argumentação e consenso. Trata-se da dificuldade encontrada pela modernidade em desenvolver qualquer discussão mais aprofundada sobre a noção de culpabilidade.

No positivismo naturalista, o juízo sobre a culpabilidade do agente não se ocupava das circunstâncias nas quais o sujeito viria a praticar o ilícito. Assim, o positivismo ignorava as causas de exculpação do autor do crime (CAMARGO, A., 1996, p. 120). Em contrapartida, embora o neokantismo houvesse permitido, no âmbito da culpabilidade, a análise sobre a exigibilidade de atuação conforme o Direito, essa avaliação se mostrava demasiado restrita, na medida em que tinha por pressuposto a existência de valores a priori válidos de maneira universal (CAMARGO, A., 1996, p. 124). O advento do finalismo pouco modificou essa realidade, uma vez que apenas substituiu o locus das estruturas apriorísticas responsáveis pela universalidade dos valores: não mais na cabeça do sujeito, como no neokantismo, e sim na realidade objetiva do ser, a partir da noção das estruturas lógico-objetivas (WELZEL, 1975, p. 1 et seq.; CAMARGO, B., 2015, p. 88-91).

Assim, no espírito da modernidade, o juízo de culpabilidade é incapaz de reconhecer a pluralidade de valores entre os diversos grupos sociais, aplicando métrica idêntica para todos os cidadãos independentemente de suas condições pessoais, e,

cidadãos (GÜNTHER, 1998b, p. 323 et seq.). 
sobretudo, desprezando a necessidade de respeito à convicção moral de cada indivíduo como condição para a legitimação da intervenção jurídica. Por isso, a modernidade no Direito Penal seria caracterizada pela notória cegueira no que tange ao papel central da dignidade humana como elemento fundante do Estado Democrático de Direito. (CAMARGO, A., 1996, p. 124 et seq.).

A crítica a uma concepção opressora de autonomia individual, que apenas sujeita o indivíduo aos interesses do grupo social, traz a lume outra ordem de investigação contida na declaração de culpabilidade. Mais do que simples categoria formal do delito, em realidade, a culpabilidade envolve uma discussão material acerca da legitimidade de imposição de uma pena a alguém, por meio de um processo criminal institucionalmente estabelecido. Esse viés material sobre a culpabilidade ficou encoberto na dogmática penal durante muito tempo (KINDHÄUSER, 2015, p. 184-185). Contudo, a discussão sobre a legitimidade da declaração de culpabilidade se faz inadiável diante do pluralismo valorativo que caracteriza as sociedades atuais.

Sem dúvida, a obra de Günther é paradigmática nesse sentido quando reforça a importância de que o indivíduo não seja visto tão somente em seu papel de destinatário da norma penal, e sim, verdadeiramente reconhecido em seu papel de criador da norma, cujo respeito é devido perante os demais membros da comunidade jurídicopolítica. Desde essa perspectiva, uma compreensão legítima de culpabilidade deve incluir o direito de participar no processo deliberativo democrático, a fim de que o cidadão tenha espaço de fala no momento de criação da norma penal. (GÜNTHER, 2005, p. 245 et seq.; GÜNTHER, 1998a, p. 80 et seq.).

O debate apresentado por Günther a respeito da legitimação do Direito Penal no Estado Democrático de Direito é de grande profundidade. Sua complexidade vem aos poucos sendo assimilada pela dogmática jurídico-penal, não obstante acompanhada de críticas contundentes (SILVA SÁNCHEZ, 2013, p. 718 et seq.).

\section{Considerações finais}

As correntes funcionalistas penais encetaram um profundo e enriquecedor debate quanto à legitimidade e limites do Direito Penal, o que merece ser reconhecido independentemente da adesão ou não a seus pressupostos.

Desde a influência de Luhmann no discurso sobre a pena, percebe-se a importância teorética dos sistemas para o pensamento jurídico-penal contemporâneo valendo menção o advento da ideia da prevenção geral positiva ainda nos anos 70 do século passado como uma nova teoria de reflexão para justificar a sanção criminal, concebendose a pena como exercício de fidelidade do Direito, até as posteriores concepções de Jakobs sobre o Direito Penal do inimigo - perpassando-se pela influência de Habermas 
no questionamento da construção jurídica com categorias apriorísticas universalmente aceitas.

Referidos autores, ao lado de outros, de algum modo, mudaram a maneira de enxergar o Direito Penal, trazendo questionamentos e inquietações que causam dúvidas ainda atuais em relação a antigos paradigmas. Talvez esse tenha sido, mais que tudo, o objetivo maior de Chaves Camargo. Trazendo como maior certeza a necessidade de dúvida permanente, insculpiu o mestre que:

\begin{abstract}
É chegado o momento de reencontrarmos a via pela qual o Direito possa reafirmar suas funções. Este, como já dissemos, é o momento da reflexão, para, através de estudos filosóficos-jurídicos, termos fundamentos adequados para os caminhos que o ser humano fixa a cada momento, através da ciência ou da tecnologia, sob pena de formarmos juristas condicionados a uma visão ilusória do papel do Direito, ou transformarmos este estudo numa massificante e cansativa atividade rotineira, sem qualquer objetivo social. (CAMARGO, A., 2016, p. 116-117).
\end{abstract}

São Paulo, março de 2019.

\title{
Referências
}

ALVES, Alaôr Caffé. Dialética e direito: linguagem, sentido e realidade. Barueri: Manole, 2010.

CAMARGO, Antonio Luis Chaves. Contradições da modernidade e direito penal. Revista Brasileira de Ciências Criminais, São Paulo, v. 4, n. 16, p. 114-126, out./dez. 1996.

CAMARGO, Antonio Luis Chaves. Imputação objetiva e direito penal brasileiro. São Paulo: Cultural Paulista, 2002.

CAMARGO, Beatriz Corrêa. O finalismo no direito penal brasileiro: uma abordagem crítica da ciência jurídico-penal no Brasil. In: SILVEIRA, Renato de Mello Jorge; SALVADOR NETTO, Alamiro Velludo; SOUZA, Luciano Anderson de. (coord.). Direito penal na pós-modernidade: escritos em homenagem a Antonio Luis Chaves Camargo. São Paulo: Quartier Latin, 2015.

CAMPILONGO, Celso Fernandes. O direito na sociedade complexa. São Paulo: Max Limonad, 2000.

DE GIORGI, Raffaele. Direito, tempo e memória. Tradução de Guilherme Leite Gonçalves. São Paulo: Quartier Latin, 2006.

GÜNTHER, Klaus. A culpabilidade no direito penal atual e no futuro. Revista Brasileira de Ciências Criminais, São Paulo, v. 24, p. 79-92, 1998a. 
GÜNTHER, Klaus. Die zuschreibung strafrechtlicher verantwortlichkeit auf der grundlage des verstehens. In: LÜDERSSEN, Klaus (org.). Aufgeklärte kriminalpolitik oder kampf gegen das böse? Baden-Baden: Nomos, 1998b. v. 1.

GÜNTHER, Klaus. Möglichkeiten einer diskursethischen begründung des strafrechts. In: JUNG Heike; MÜLLER-DIETZ, Heinz; NEUMANN, Ulfrid (org.). Recht und moral: beiträge zu einer standortbestimmung. Baden-Baden: Nomos, 1991.

GÜNTHER, Klaus. Schuld und kommunikative Freiheit: studien zur personalen zurechnung strafbaren unrechts im demokratischen rechtsstaat. Frankfurt am Main: Vittorio Klostermann, 2005.

HABERMAS, Jürgen. O filósofo como verdadeiro professor de direito. Tradução Rúrion Soares Melo. Revista Direito GV, São Paulo, v. 1, n. 2, p. 179-190, jun./dez. 2005.

HASSEMER, Winfried. Puede haber delitos que no afecten a un bien jurídico penal? In: HEFENDEHL, Roland; HIRSCH, Andrew von; WOHLERS, Wolfgang (ed.). La teoría del bien jurídico: ¿fundamento de legitimación del derecho penal o juego de abalorios dogmático? Madrid: Marcial Pons, 2007.

HERRERO, Francisco Javier. Jürgen Habermas: teoria crítica da sociedade. Síntese, Belo Horizonte, v. 6 , n. 15 , p. 11-36, 1979.

JAKOBS, Günther. Das Strafrecht zwischen Funktionalismus und „alteuropäischem” Prinzipiendenken. Zeitschrift für die gesamte Strafrechtswissenschaft, München, v. 107, n. 4, p. 843-876, 1995.

KINDHÄUSER, Urs. Strafrecht: allgemeiner teil. Baden-Baden: Nomos, 2015.

LUHMANN, Niklas. Sociologia do direito. Trad. Gustavo Bayer. Rio de Janeiro: Tempo Brasileiro, 1983. v. 1.

MATURANA, Humberto R.; VARELA, Francisco J. Autopoiesis and cognition: the realization of the living. Dordrecht: D. Reidel, 1980.

NEVES, Rômulo Figueira. Entrevista com Marcelo Neves: a teoria dos sistemas sociais de Niklas Luhmann. Plural, São Paulo, v. 11, p. 121-133, 2004. Disponível em: http://www.revistas.usp.br/ plural/article/view/68086/78823. Acesso em: 11 jun. 2018.

PAWLIK, Michael. Ciudadanía y derecho penal: fundamentos de la teoría de la pena y del delito en un estado de libertades. Traducción Ricardo Robles Planas; Nuria Pastor Muñoz; Ivó Coca Vila e Héctor García de la Torre. Barcelona: Atelier, 2016.

PÜSCHEL, Flavia Portella; MACHADO, Marta Rodriguez de Assis. Teoria da responsabilidade no Estado Democrático de Direito: textos de Klaus Günther. São Paulo: Saraiva, 2009.

ROXIN, Claus. Derecho penal: parte general: fundamentos: la estructura de la teoría del delito. Trad. Diego-Manuel Luzón Peña, Miguel Díaz y García Conlledo e Javier de Vicente Remesal. Madrid: Civitas, 2008. Tomo 1. 
SCHÜNEMANN, Bernd. Consideraciones críticas sobre la situación espiritual de la ciencia jurídico-penal alemana. Anuario de derecho penal y ciencias penales, Madrid, v. 49, n. 1, p. 187-218, 1996. Disponível em: https://www.boe.es/publicaciones/anuarios_derecho/abrir_pdf. php?id=ANU-P-1996-10018700218.

SIEBER, Ulrich. Limites do direito penal: princípios e desafios do novo programa de pesquisa em direito penal no Instituto Max-Planck de direito penal estrangeiro e internacional. Tradução Alessandro Hirata. Revista Direito GV, São Paulo, v. 4, n. 1, p. 269-330, jan./jun. 2008.

SILVA SÁNCHEZ, Jesús-María. Presupuestos socio-políticos de la atribuición de responsabilidad penal. In: GONZÁLEZ TASCÓN, María Marta; VILLA SIERO, Sonia Victoria; FERNANDÉS TERUELO, Javier Gustavo (coord.). Estudios penales en homenaje al profesor Rodrigo Fabio Suárez Montes. Oviedo: Constitutio Criminalis Carolina, 2013.

TEUBNER, Gunther. $O$ direito como sistema autopoiético. Trad. José Engrácia Antunes. Lisboa: Fundação Calouste Gulbekian, 1989.

WELZEL, Hans. Strafrecht und philosophie. In: WELZEL, Hans. Abhandlungen zum strafrecht und zur rechtsphilosophie. Berlin: Walter de Gruyter, 1975. 